\title{
Energy Transfer between Calixarene and Naphthalene
}

\author{
Seong-Keun Kook

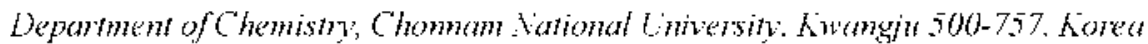 \\ Received June +, 2002
}

\begin{abstract}
The photoluminescence of calixarene crystals has been studied as functions of temperature, time, and concentration. The vibronic bands shift to longer wavelength and become significantly sharper as temperature decreases. The experimental results reveal that the structural transtomation occur during the annealing process. 'lime-resolved spectra of calixarene at $12 \mathrm{~K}$ are monitored. Spectral features, which demonstrate characteristic of energy transter processes. are not obser ed. The depopulation of excited state density is mainly controlled by unimolecular decay process dominating other decav processes. The lifetime was found to be $2.6 \pm 0.1 \mathrm{~ns}$. For the case of calixarene mixed with naphthalene, the fluorescence spectrum shows that the band centered at $340 \mathrm{~nm}$ lies $2840 \mathrm{~cm}{ }^{\prime}$ below the relatively broad $310 \mathrm{~nm}$ band found for calisarene cry stals. The spectra also exhibit that the emission intensity increases with increasing calisarene concentration. The results are exident that the calixarene emission is quenched by the naphthalene. P'hosphorescence of calisarene mixed with naphthalene crystals is observed to detemine whether the emission is due to naphthalene. The phosphorescence peaks were compared with the ground-state vibrational frequencies of naphthalene and found to be in good agrement. The results indicate that inter-molecular energy transfer occurs between calisarene and naphthalene.
\end{abstract}

Key words : I, uminescence, Tnergy transler, Calixarene, Naphthalene

\section{Introduction}

The stidy of calixarene has been of continuing research interest in the areas of host-guest chemistry ${ }^{1-1}$ inclusion compounds. ${ }^{5-?}$ organic catalysts, ${ }^{89}$ and analytical chemistry. ${ }^{10,11}$ Solid state host-guest systems have provided much spectroscopic information about molecular properties. The lack of universal host material that forms single crystal and is a solid at room temperature has been a significant problem. It appears that calixarene may be the solution to this problem. Calixarene is methylene linked phenolic macrocycles available in several cavity sizes, and a variety of functional groups at the top and bottom rims of cavity: Calixarenes could have four possible geometrical structures such as cone. partial cone, 1,2-alternate. and 1.3-alternate. ${ }^{12-14}$ Calixarene has attracted researchers attention because it has remarkable chemical ability to dissolve a wide variety of other compounds. both in solution and in the solid state. Calixarene forms inclusion compounds by dissolving other molecules to form crystalline solids. These inclusion compound can be formed with essentially any gnest. The selectivity and orientation of guest molecules in the cavity depend on the size and functional group of guest molecules. ${ }^{17}$ The calixarene crystals have well defined structures and stoichiometries and sufficiently small disorder that even atoms of the guest molecules can be located by X-ray crystallography: ${ }^{1.3}$ For these reasons. calixarene may sene as a universal host for spectroscopic studies and technological application of molecular solid guest-host system. but essentially nothing is known about the optical properties of these material. although some characteristics have been reported. ${ }^{1-19}$

Much of the previous photoluminescence works on calixarene has been done on porous silicon coated with calixarene. ${ }^{1.5}$ on water-soluble calixarene, ${ }^{16-18}$ or on LangmuirBlodgett films. ${ }^{19}$ Zhang and coworkers ${ }^{15}$ studied the luminescence quenching effect for porous silicon coated with calixarene carboxylic acid derivatives. The experimental results demonstrate that calixarene can form thin films on the surface of $\mathrm{Si}$. This yields a stable interface in aquous media demonstrating selectivity regard to photoluminescence quenching behavior dependent on the size of the calixarene. Carbosylic acid groups play an important role in the photoluminescence enhancement of porous silicon. Gravett and coworkers ${ }^{1 ?}$ reported the sy ntheses of a novel calixarenecontaining monomer. Free radical polymerization of the calixarene containing monomer with 2-(6-sulfo-2-naphthoxy)ethyl methacrylate sodium salt resulted in a watersoluble polymer. The antemu polymers have proved interesting in attempt to mimic the processes incolved in photosynthesis. These antemu polymers showed to solubilize various organic probe molecules, while the presence of the chromophore gives them ability to transfer energy absorbed by the polymer to solubilized probe molecules which can lead to the sensitized photochenical reaction of these solubilized probe molecules. They determined the location of the solubilized probe molecules within the polymer. Grady and coworkers ${ }^{18}$ monitored the quenching of the fluorescence of chiral calixarene solution to determine the enantiomeric composition of chiral amines. They determined the enantiomeric composition of samples of (R)- and (S)phenylethy lamine and L- and D-norephedrine to within few percent. Nabok and coworkers ${ }^{19}$ reported the formation and characterization of CdS nanoparticles in calixarene LangmuirBlodgett (LB) films. They monitored UV-vis absorption 
spectra to check the presence of CdS nanoparticles in LB film matrices. The experimental results demonstrated that the particle size does not depend on the type of calixarene or the number of LB layers.

Here we report the in estigation of the photoluminescence for calixarene cry stals as functions of temperature, time, and concentration. The particular derivatives of calivarene interested in this study contain butyl groups on their upper nim and lydroxyl groups on the lower rim with four phenol moieties. This paper also report the observation of the energy transfer phenomena between calixarene and naphthalene from fluorescence decay and the sensitized phosphorescence. Naphthilene was chosen because a wealth of spectroscopic information has been accumulated on naphthalene molecules. and neat and mixed cry stals of naphthalene. . $^{3(1-28}$

\section{Experimental Techniques}

Calixarene crystals were prepared by slow cooling followed by slow exaporation of the solvent. After crysallization. the resulting cry stals were rinsed with solvent. Naphthalene $\left(\mathrm{C}_{11} \mathrm{H}_{8}\right)$ was purified by multiple (four times) recrystallization from ethanol, and zone-refined for 100 passes at a velocity of 1 incl//hour. To obtain mixture of calixarene with naphthalene. appropriate amount of naphthalene and calixarene were mixed and then dissolved using ethanol as a solvent. To determine whether the calixarene forms inclusion compound or not. i.e. naphtalene locate in the cavity of calixarene or between calixarene molecules. NMR spectrum was analyzed. The NMR spectrum shows that maphthalene locates between calixarene molecules.

The crystals were mounted between a quartz plate and in the closed cycled cryogenic system (APD CSW-202) to obtain the temperature between $12 \mathrm{~K}$ and $298 \mathrm{~K}$. The excited states were generated by $325 \mathrm{~mm}$ radiation from a $\mathrm{He}-\mathrm{Cd}$ laser (Liconix $3650 \mathrm{~N}$ ) or by $266 \mathrm{~mm}$ from th generation of pulsed Nd-YAG laser (SL825G. spectra laser sy stems). The emission was focused onto the entrance slit of a $0.85 \mathrm{M}$ double spectrometer (Spex 1403). The photosignal was

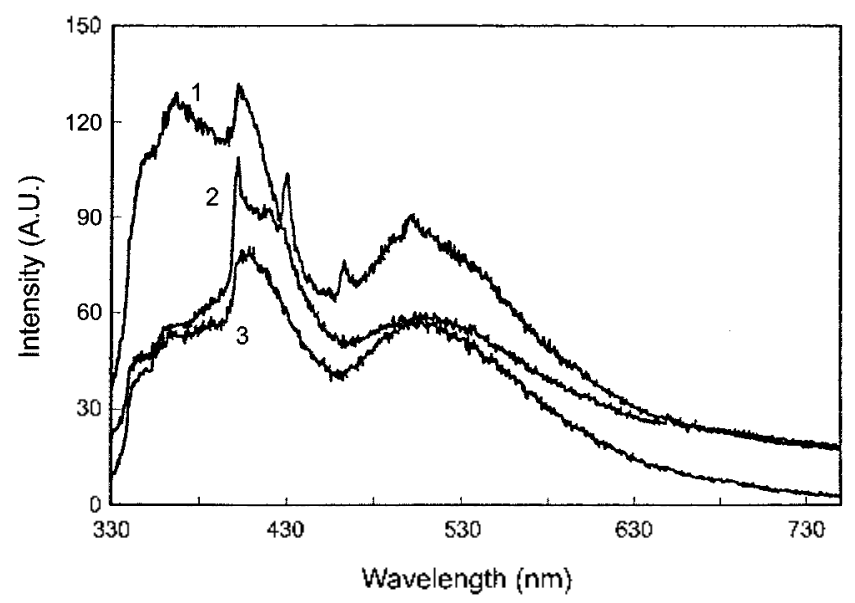

Figure 1. A sel of sleady-slate luminescence spectra of calivarenc cristals for different temperatures obtainled with .325 mu excitation (1: at $298 \mathrm{~K}, 2: 12 \mathrm{~K}, 3: 298 \mathrm{~K}$ after anmealing)

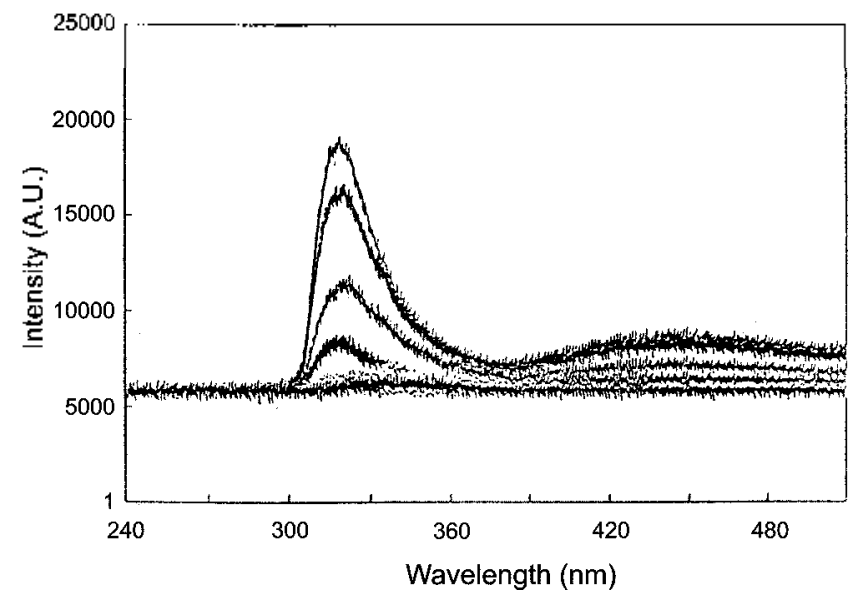

Figure 2. Time-resolved spectra of ealixarene at $12 \mathrm{~K}$ for diflerent delay limes with excitation at $266 \mathrm{~mm}$ (increment of delay time is 1 nis).

detected with an a photomultiplier tube (Hamamatsu R943$02 \mathrm{GaAs}$ ) and amplified using a current amplifier at a gain of $10^{*} \mathrm{~V} / \mathrm{A}$. A photon counter was used for the time-resolved data acquisition. The time response of the electronics was tested with a pulse generator. All the experiments were controlled by a computer. The spectra were collected using an analog to digital converter.

\section{Experimental Results}

A set of steady-state luminescence spectra of calixarene crystals for different temperatures obtained with $325 \mathrm{~nm}$ excitation is shown in Figure 1. For the case of spectrum at $298 \mathrm{~K}$. steady-state fluorescence shows the three vibronic modes at $365 \mathrm{rm}, 402 \mathrm{~nm}$. and $500 \mathrm{~mm}$. As temperature decreases to $12 \mathrm{~K}$. the band at $365 \mathrm{~lm}$ significantly decreases in intensity and relatively sharp peaks appear at $402 \mathrm{~nm}$ and $430 \mathrm{mml}$, and the broad band at $500 \mathrm{~nm}$ increases in intensity: The spectrum observed at $298 \mathrm{~K}$. obtained after increasing temperature from $12 \mathrm{~K}$ (annealing), resembles that of the spectrum obtained at $12 \mathrm{~K}$. but relatively broad due to thermally activated dispersions.

Time-resolved spectra of calixarene at $12 \mathrm{~K}$ for different delay times following excitation are shown in Figure 2. The excitation energy was $266 \mathrm{rm}$ and the increment of delay time was lns. The width and position of the band appear to be independent of the delay time. The linear semilog plot indicates that the time evolution of the fluorescence intensity of calixarene crystals is a simple exponential function of time. The life time was found to be $2.6 \pm 0.1 \mathrm{~ns}$. Delayed fluorescence was not detectable under the experimental condition used.

Steady-state fluorescence spectra of calixarene mixed with different concentrations of naphthalene obtained at $12 \mathrm{~K}$ with $266 \mathrm{~mm}$ excitation are shown in Figure 3. The spectra show that the broad band centered at $340 \mathrm{~nm}$ lies $2840 \mathrm{~cm}^{-1}$ below the relatively broad $310 \mathrm{~mm}$ band found for calixarene crystals. The broad band contains the relatively sharp spectral features at $332 \mathrm{~nm} .337 \mathrm{~nm} .342 \mathrm{~nm}$. and $352 \mathrm{~nm}$ 


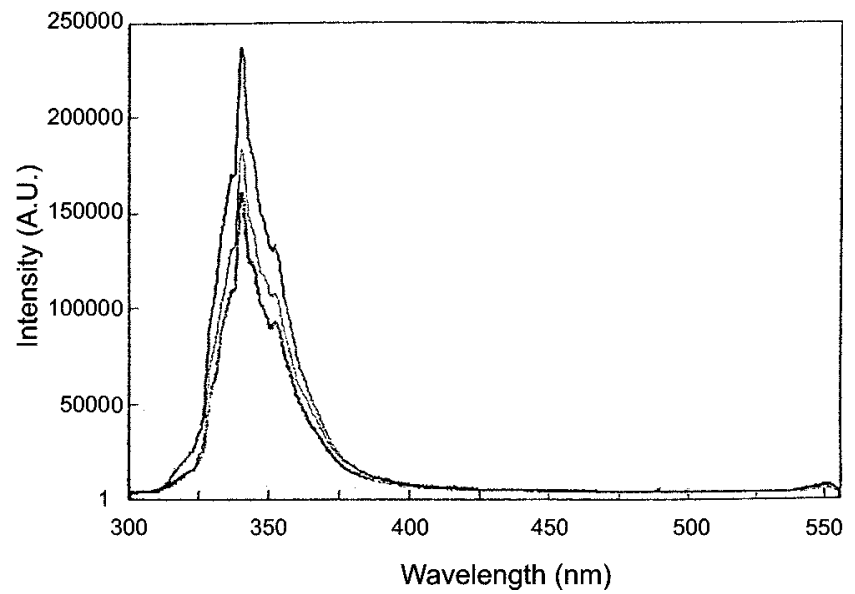

Figure 3. The lluorescence spectra of ealixarene mixed with dillerent concentrations of naphithalemes obtained at $12 \mathrm{~K}$ it ith 260 $11 \mathrm{~m}$ excitation (the mole ratio of calixarene: naphthalene are top: 3: 1, middle: $2: 1$, bottom: I: 1).



Figure 4. 'The phosphorescence of calixarene mixud with naphthalene obtained at $12 \mathrm{~K}$ with $266 \mathrm{~mm}$ excitation.

which is significantly different from that of calixarene shown in Figure 2. It is assumed that the emission of calixarene is quenched by naphthalene. The broad band presumably is due to a disordered structure. The spectrum also show that the increase of calixarene concentration results in an increase in the fluorescence emission of naphthalene. The results are evident that the calixarene emission is being quenched by the presence of the naphthalene.

The phosphorescence spectnum of calixarene mixed with naphthalene obtained at $12 \mathrm{~K}$ with $266 \mathrm{~mm}$ excitation is shown in Figure 4 . The observed phosphorescence peaks appeared at $472 \mathrm{~nm} .483 \mathrm{~nm} .505 \mathrm{~mm}$. and $510 \mathrm{~nm}$. To determine whether the emission is due to naphthalene, the ground-state vibrational frequencies were compared with those for naphthalene and found to be in good agreement.

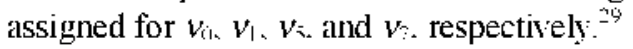

\section{Discussion}

First. we consider the experimental results for calixarene photoluminescence as a function of temperature. The experimental results, as shown in Figure 1, show significant changes in spectral features as temperature decreases from $298 \mathrm{~K}$ to $12 \mathrm{~K}$. The spectrum obtained after increasing temperature from $12 \mathrm{~K}$ to $298 \mathrm{~K}$ (anmealing), however. does not demonstrate the spectral features of the spectrum at $2 \% 8$ $\mathrm{K}$ obtained before anmealing. The spectrun is similar to one at $12 \mathrm{~K}$. but relatively broad which may be due to thernally activated dispersion. It is assumed that the spectrum at $298 \mathrm{~K}$ is connected with the luminescence of free excitons and the spectrum at low temperature is luminescence of excitons localized on structural defects. A luminescence spectrum was obtained with higher excitation energy. We expect the changes in the spectral position and bandwidth as density of states increases if the excitons fall into traps of the structural defects. No significant change in spectral features is observed. This results rule out the assumption becaluse higher exciton population would increase the trapping efficiency to the structural defects and cause the spectra slift to longer wavelength. We now consider that there is a structural transformation from high temperature modification to low temperature modification as temperature decreases. Figure 1 also shows the spectrum at temperature of $298 \mathrm{~K}$ for the crystals after cooling down to $12 \mathrm{~K}$. The band position of spectrum at $298 \mathrm{~K}$ after frequent cooling (anmealing process) resembles the spectrum of $12 \mathrm{~K}$. The experimental results demonstrate that the consideration of structural transformation seems to be quite reasonable. The changes of the spectral features may take place due to local temperature of sample by laser illumination. In order to determine this is not the case. the sample was cooled down to $12 \mathrm{~K}$ and heated to $298 \mathrm{~K}$ without laser illumination. The luminescence obtained for crystal annealed without laser illumination is identical with the one for the sample laser illuminated in the process of annealing. From the experimental results we conclude that the structural transformation occurs during the annealing process.

The experimental results of time-resolved spectra of calixarene at $12 \mathrm{~K}$ demonstrate that the width and position of the band appear to be independent of the delay time. If there is an energy transfer from a high to low energy sites. we expect changes in spectral features. If energy transfer process is controlled by emission of phonons or vibrons, the excess energy must be dissipated by phonons or vibrons and a higher energy band will lose intensity and a lower energy band will gain intensity follow ing the time of excitation. The experimental results imply that no site relaxation occurs after a site has been populated by an excitation. Low temperature luminescence spectra of matrix-isolated organic molecules usually exhibit a well-resolved zero phonon feature suggesting that spontaneous site relaxation after excitation is the exception rather than the rule. iti-ì $^{\text {if }}$ the density of states controls the rates, the band will gradually broaden and shift to lower energy sites. No cascade relaxation, however, is observed. The results indicate that the depopulation of excited state density is mainly controlled by unimolecular decay processes dominating other decay 
processes. The linear semilog plot indicates that the time evolution of the fluorescence intensity of calixarene crystals is a simple exponential function of time. The lifetime of calixarene in the singlet excited state is found to be $2.6 \pm 0.1 \mathrm{~ns}$.

Now we consider the experimental results of calixarene mixed with naphthalene. Figure 3 shows the fluorescence spectra of calixarene mixed with naphthalene at $12 \mathrm{~K}$ obtained with 266 run excitation. The spectrum shows that the broad band centered at $340 \mathrm{~nm}$ lies $2840 \mathrm{~cm}^{-1}$ below the relatively broad 310 num band found for calixarene crystals. The broad band contains the relatively sharp spectral features at $332 \mathrm{~nm} .337 \mathrm{~mm}, 342 \mathrm{~nm}$. and $352 \mathrm{~mm}$ which is significantly different from that of calixarene crystals shown in Figure 2. It is assumed that calixarene emission is quenched by naphthalene. The broad band presumably is due to a disordered structure of calixarene. Calixarene can generally have four different conformations: cone. partial cone. 1,2-alternate. and 1,3-alternate. ${ }^{1-1+}$ Shinkai and coworkers $^{33}$ have shown that calixarene contains various ratio of mixture of four confonnations depending on the experimental condition. In addition to these basic types of conformational isomers. there also be cases where the substituents are either inside or outside. ${ }^{34}$ The disordered structure of calixarene would produce the spectral broad band. In order to determine whether the emission is due to naphthalene. phosphorescence of calixarene mixed with naphthalene was observed. as shown in Figure $t$. The phosphoresnce peaks appeared at $47 \mathrm{l} \mathrm{rm}, 483 \mathrm{lml} .505 \mathrm{~nm}$. and $510 \mathrm{~nm}$ were compared with those for naphthalene and found to be in good agreement. These peaks correspond to the ground-state vibrational frequencies of naphthalene crystals. $v_{1}, v_{1}, v_{5}$ and $v_{3}$. respectively ${ }^{29}$ Therefore. we conclude that spectrum is attributed to emission of naphthalene. i.e. calixarene emission is quenched by naphthaleme. Figure 3 also show the fluorescence spectra of calixarene mixed with different concentrations of naphthalene. The results demonstrate that increase of calixarene concentration results in an increase in the fluorescence emission of naphthalene. The result is evident that the calivarene emission is being quenched by the presence of naphthalene. In order to understand the concentration dependence of energy transfer. we consider the spatial distribution of naphthalene molecules among the calixarene molecules. Three possible configurations for the spatial distribution can be imagined: (A) separate phase of calixarene and naphthalene molecules. (B) stoichiometric mixture of calixarene and naphthalene with a separate phase of excess calixarene and (C) calixarene with guest sites partially filled with naphthalene molecules. i.e. not all the arailable guest sites are occupied by naphthalene molecules. For configuration (A), energy transfer between calixarene and naphthalene is only possible at the phase boundaries. This situlation would not produce a concentration effect on energy transfer. Configuration (B) would not show any concentration effect at all. The observed experimental results provide characteristic of a random distribution of naphthalene molecules and serve to identify the configuration (C).

\section{Summary and Conclusions}

The luminescence of calixarene crystals has been studied as a function of temperature. The experimental results slow that there are significant changes in spectral features as temperature decreases from $298 \mathrm{~K}$ to $12 \mathrm{~K}$. The spectrum obtained after increasing temperature from $12 \mathrm{~K}$ to $298 \mathrm{~K}$ (annealing process), however, does not demonstrate the spectral features of the spectrum at 298 before annealing. The spectrum is similar to one at $12 \mathrm{~K}$. but relatively broad which may be due to thernally activated dispersion. The experimental results reveal that a structural transformation from high temperature modification to low temperature modification occurs during the annealing process. The experimental results of time-resolved spectra of calixarene at $12 \mathrm{~K}$ demonstrate that the width and the position of the emission band appear to be independent of the delay time. The results indicate that no energy transfer processes occur and the depopulation of excited state density is mainly controlled by unimolecular decay processes doninating other decay processes. The lifetime of calixarene in the singlet excited state is found to be $2.6 \pm 0.1 \mathrm{lls}$.

For the case of calixarane mixed with naphthalene, the spectrum shows that the broad band centered at $340 \mathrm{~nm}$ lies $2840 \mathrm{~cm}^{-1}$ below the relatively broad $310 \mathrm{~nm}$ band found for calixarene crystals. The broad band contain the relatively sharp spectral features which is significantly different from that of calixarene crystals. In order to determine whether the emission is due to naphthalene. phosphorescence spectrum of calixarene mixed with naphthalene crystals is observed. The phosphorescence peaks were compared with those for naphthalene and found to be in good agreement. The fluorescence spectra of calixarene mixed with different concentrations of naphthalene were observed. The experimental results demonstrate that increase of calixarene concentration results in an increase in the fluorescence emission of naphthalene. The result is evident that the calixarene enission is being quenched by the presence of naphthalene. Therefore we conclude that energy transfer takes place between calixarene and naphthalene. In order to understand the concentration dependence of energy transfer. the spatial distribution of naphthalene molecules among the calixarene molecules was considered. The observed experimental result provides characteristic of a random distribution of naphthalene molecules. i.e. calixarene with guest sites partially filled with naphthalene molecules, not all the available guest sites are occupied by naphthalene molecules.

Acknowledgment. This work was financially supported by Chonnam National University: The author thanks to professor Kye-Chun Nam. Department of Chemistry. Chonnam National University for providing calixarene crystals.

\section{References}

1. Gutsche. C. D. .ice. ('he'm. Re's. 1983. /6. I61

2. Calixanenex. Stoddart. I. F.. Ed: Royal Sociely of Chemistry: 
Cambridge. 1989.

3. Arimura. T.: Kawabala. H.: Matsuda. l.: Muramalsu. l.: Saloh. H.: Fugio. K.: Manabe P': Shinkia. S. J. Org. Chem. 1991. 56. 301.

4. Takeshita, M.: Shinkai. S. Bull. Chm. Soc. Jpm. 1995, 68(4), 1088 .

5. Alwood. J. L.: Sreed. J. W. Wefal-atom Appended ('alixarnes and Related Host ('ompownds. 8th Intenational Symposium on Molecular Recognition and Inclusion: Ottana. Ontario. Canada. 1994.

6. Atwood, J. W.: Koptsantonis. G. A.: Raston, C. I. Aanne 1994. 368.229

7. Xu. W.: Vital. J.: Puddephatt. R. J. J. 1m. (hem. Soc. 1995. //7. 8362.

8. Araki. K.: Yanagi. A.: Shinkai. S. Tetahedton 1993. t9(31). 6763

9. Gatsch. C. D.: Alam. I. Ketwh tron 1988, 44. 4689

10. Calestani, G.: Ugorzoli, F.: Gloidini, F.: Ungaro, R. J. Chom. Soc. Chem. Comm. 1987, 344.

11. Yamamolo. H.: Shinkai. S. (Wem. I.ett 1994. 1115.

12. Gulsche. C. D.: Levine. J. A.: No. K. H.: Bater. L. Tetrathdron 1983. 39. 409

13. Park, Y. J.: Shin, J. M.: Nam, K. C.: Kim, J. M.: Kook. S. K. Bull. Nonem Chem. Sex. 1996. 17. 643

14. Gutsehe, C. D. Calixantes: Roval Society of Chemistry: Cambridge. 1989.

15. Zliang. L.: Coller. J. L.: Wang. J.: Gulsche. C. D. J. im. Chem Soc. $1990.1 / 1.12840$

16. 7.hang. Y.: Agbaria, R. A.: Mukundan. N.: Warner, I. J. Inctusion Phonem. amd Hol. Recergn. in Chemistry 1996, 24. 35.3
17. Gravelt. D. M.: Guillet. J. E. Macrnolecules 1946. 29.617.

18. Grady. T.: Harris. S. J.: Smylh. M. R.: Diamend. D. Lhal Chem. 1996. 68. 3775

19. Nabok, A. V.: Richardson, T.; Daries, [..: Stirling. J. M. Langmuir 1997, 13. 3198

20. Dunach, M.: Seigneuret. M.: Rigaud, J. I.: Padros. F. Biochemistm 1987. 26. 1179 .

21. Chang. C. H.: Chen. J. G.: Govindjee. R.: Ebrey. I. Proc. Watl.

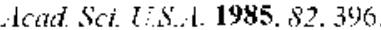

22. Chang. C. I1.: Jonas, R.: Melchiore. S: Crovindjec. R.: F.brey. T. G. Biophis J. 1986. 49.731.

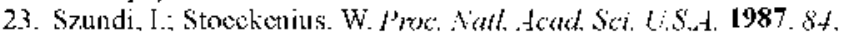
3681 .

24. Szundi. I.: Stoekenius. W. Biophus. J. 1988. 54.227.

25. Szundi. I.: Stoekenius. W. Biophus. J, 1989. 56. 369 .

26. Nriki, M. I anyi, J. K. J. Biol. Chem. 1986. 261.8167

27. Jonas, R.: Koumlos. Y.: T.brer, T. G. Ihotochem. Phowotiol 1990 52.116 .3

28. Jonas. R.: Ebrev T. G. Proc. Fatl doad Sci T.S.d. 1991. 88. 149

29. Hanson. D. M.J. (Them. 1969.5I. 11.

30. Personox. R. I. In Spectroscopy and Fxcitatom Dimamics of Condensed Molecular Sistems: $\Lambda$ gratnoxich, V. M.: IIochstrasser. R. M.. Fds.: North-H Iolland: Amsterdam. 1983.

31. Funfschilling. J.; 7.schocke-Gratnacher. J. Chem. Thes. Lett. 1984. 110. 315 .

32. Jankon iak. R.: Bassler. H. Chem Phs. 1984. 89.81.

33. Araki. K.: Iwamoto. K.: Shinkai. S.: Matsuda. T. (Wen Left. 1989,1747

34. Iwamoto, K.: Araki, K: Shitkai, S. J. Ory. Chem. 1991, 56.4955. 